\section{SOI: $1.1 / \mathrm{TAS} \quad$ DOI: $10.15863 / \mathrm{TAS}$ \\ International Scientific Journal Theoretical \& Applied Science}

p-ISSN: 2308-4944 (print) e-ISSN: 2409-0085 (online)

Year: $2017 \quad$ Issue: $02 \quad$ Volume: 46

Published: 28.02.2017 http://T-Science.org

SECTION 8. Architecture and construction.
Manuchar Tamazovich Shishinashvili

Doctor of engineering Sciences, Professor national defence Academy of Georgia

Georgian Technical University m.shishinashvili@gmail.com

Vaxtang Teimurazovich Jghamaia Doctor of engineering Sciences, Professor Georgian Technical University vighamaia@yahoo.com

Aleksey Robizonovich Burduladze Doctor of technical Sciences, Professor national defence Academy of Georgia

Georgian Technical University burdato@yahoo.com

Girogi Anzorevich Chubinidze Doctor of engineering Sciences, Professor Georgian Technical University gioxashuri@gmail.com

\title{
PECULIARITIES OF FLEXIBLE PAVEMENT CONSTRUCTION WITH CONSIDERATION OF EXISTING CLIMATIC CONDITIONS IN GEORGIA
}

\author{
Abstract: Presented work considers peculiarities of flexible composite pavement construction, under existing \\ climatic conditions in Georgia. \\ Simultaneously, technological characteristics of construction of flexible composite pavements with positive \\ aspects are clearly illustrated. Examples are given to demonstrate advantages of operational characteristics of \\ flexible composite pavements. \\ Key words: Road surface, Bitumen, Asphalt \\ Language: English \\ Citation: Shishinashvili MT, Jghamaia VT, Burduladze AR, Chubinidze GA (2017) PECULIARITIES OF \\ FLEXIBLE PAVEMENT CONSTRUCTION WITH CONSIDERATION OF EXISTING CLIMATIC \\ CONDITIONS IN GEORGIA. ISJ Theoretical \& Applied Science, 02 (46): 139-142. \\ Soi: http://s-o-i.org/1.1/TAS-02-46-25 Doi: crossef https://dx.doi.org/10.15863/TAS.2017.02.46.25
}

\section{Introduction}

Principal pavement material used throughout Georgia for road network furnishing is an asphalt. That is determined by the geographic location and simplicity of arranging this type of material as a surface layer. Via accounting for climatic conditions of Georgia we would like to introduce our approach regarding construction of flexible pavements.

The road structure contains a roadbed and a road dress. The crucial part of the structure is the road dress or pavement that is durable surface material laid down on an area to tended to sustain vehicular traffic. It is the most sensitive to the impact from nature and climatic conditions.

\section{Materials and Methods}

Constructing the road dress with strengthening includes the selection of material, used for arranging construction layers, as well as tentative designation of their thickness. During constructing the pavements, due considerations shall be given to the requirements for operational quality of roads, reduction of material consumption and labor-output ratio with reference to the quality of underlying structure.

Three layers might be distinguished in road pavements: wearing course, main course of surface layer and the base. The wearing course should have required roughness, evenness and shear strength. The mentioned course might be executed as a separate element (surface treatment or special protective layers) of pavement structure or otherwise, it might be the upper layer of pavement. In separate occasions, especially while paving asphalt concrete with a low content of binder, the wearing course can bear the functions of water-protecting layer. The 
thickness of wearing course is not high, thus, this layer does not bear impact on strength or strain capacity of underlying layers. The mentioned also entails the lower heat-resistant properties of the layer.

The surface layer of flexible pavement incurs the horizontal and vertical tensions and strain from the impact by vehicular loads. Contrary to the widespread opinion, the stress from horizontal loads diminishes in accordance with the rules applied to the vertical loads and not faster, as it was accepted earlier. The surface layer distributes loads that will transfer to the base. Distribution properties of surface layer are as higher, as thicker it is and higher is its resilient modulus.

The surface layer also has the water and heatprotective properties. Under the impact of heating and cooling, in surface and base layers, the temperature tensions occur that increase due to increased differences in temperature. The highest sensitivity is observed under the daily and monthly differences in temperatures. In surface layers the temperature gradient is highest, that is why the temperature range in the base is lower than in surface layers, and i.e. the surface layers bear the heatprotective functions.

The base of the road dress distributes the loads on soil. The tensions and strain in this layer rapidly decrease. It should be underlined that, in base layers, there are less impact from temperature, than in surface layers.

The inter-relations between the surface layer and the base (i.e. bond) represent one of the components of the road pavement strength.

In case there is no sufficient bond and the layers move horizontally relative to each other, interactions diminish and slip of layer material is possible. The temperature strain of one of the layers does not impact the other. At the same time the risk of dislodgement and raveling under the vehicle load vibrations increases.

In case the bond between the surface and base layers are sound, the layers are deformed simultaneously, hereto the tensions and strain in less rigid layer increases, while in more rigid layer decreases.

Harder the upper layer, the less tensions and strain transfers to the base layer. In this case, on the contact line of two layers the tensions are accrued creating the highest danger for base. Heat-transfer properties of surface layer and a base are different. According to surveys, in contact line zone, between layers, the sharp changes in temperature were observed entailing considerable temperature gradients that might result in gradual destruction of contact zone.

For construction of pavement base course, various rock and binding materials are used. There are two criteria for selecting: the first includes strengthening of base layers with binding agents in order to increase the bearing capacity in unfavorable soil. and climatic conditions, the second implies use of tire rate. Less the strain capacity of road dress (larger resilient modulus) lesser is resistance to rolling. In a number of cases, the properties of such layers are subject to time-change (crushability, soaking values) that is crucial to consider while calculating and constructing.

Construction layers of the base of road dress with asphalt concrete surfacing shall meet some requirements as follows:

Base shall represent the flexible, seamless slab that works only in resilient phase;

Heat-transfer and mechanical properties of the base and asphalt concrete layers shall not differ considerably. Apart from this, it is crucial that the freeze-resistance and resilient modulus of the base should be less than that of surface layer, while waterresistance, strain capacity and linear expansion is desirable to be equal.

Noncompliance with these requirements diminishes the strength of existing pavement and should be taken into consideration while strengthening.

Roadbed is a foundation of road pavement and it determines the mode of deformation of entire road pavement structure. Properties of roadbed soils are less stable than that of road dress, thus entailing the wider variations of structural-and-mechanical properties under the impact from loads and waterand-heat factors, than that of road pavement.

In case of weakness of base soil, the road structure stability might be provided by increasing hardness or thickness of road dress pavement layers. The mentioned results in considerably increased expenditures.

The soil base properties alters within annual cycle, under influence of water and heat. These factors cause the moisture migration within the road bed, namely, it moves from warmer to cooler strata. Moisture migration is possible in both, in liquid phase (film or capillary moisture) as well as in vapor phase.

In winter, in a majority of climatic zones, the moisture migrates from lower layers of roadbed to upper - to the road pavement base - where moisture accumulates and freezes resulting in some degree of ground decomposition, because of water expansion after freezing.

In a rated period - springtime - the most moistened part of a roadbed is an upper layer - the base of road dress since it is characterized with the largest temperature gradients with fluctuations. The values of the mentioned gradients and their fluctuation depend on heat-shielding properties of road dress.

Since the road pavement strengthening tend to change the physical-mechanical properties of 
existing pavement, the mentioned conditions should be taken care of during strengthening and improvements of road dress.

During calculations of layers, the rational distribution of material to thickness is to be ensured, as well as reducing of layer costs with increasing depth. To put it down otherwise, the hardness of material shall decrease from top courses to down layers, i.e. in accordance with a decreasing of tensions caused by live loads. The most expedient ratio of resilient moduli of contiguous layers is between $1,5 \div 3$. Such distribution of construction layers to depths is wide-spread, though not always optimal. In designing practice, oftentimes, especially during reconstruction of road pavement, the harder layers are placed not only in upper but also lower positions. The hard foundation concentrates the tension in upper layer and this should be taken into consideration while strengthening.

\section{Conclusion}

During strengthening of existing flexible pavement the following shall be accounted for:

Strengthening layer should provide for required operation properties of road dress en masse, i. e. stability, level, skid resistance, durability, while ensuring compliance with requirements for material consumption and labor input in structure constructions;

The durability of strengthening layer, and a structure as a whole, might be ensured with sound bond between the strengthening and existing base old road dress. The mentioned requires rejecting of regulating layers constructed with unbonded material (gravel, crushed rock) while strengthening. Quasi economy of expenditures by reducing material that are processed with organic bonding agents results in faster decomposition of structures under traffic, entailing considerable, additional expenses;

In order to provide for minimal labor input, the number of layers during strengthening should be minimal. Hence, in a number of cases, it is advisable to replace two-layer asphalt concrete structures with one thickened layer. Since, while paving the thickened asphalt concrete layers are subject to slower cooling, they are consolidating under higher temperature. The bulk weight and strength of material in such layers are higher than in ordinary layers. That is why the replacement of two-course strengthening layers with one thickened layer provides for economy of organic bonding agents. One more advantage of thickened layer: during improvement of old road pavement with cracks - by constructing the thinner strengthening asphalt concrete layer - the cracks reappear on a new pavement;

During constructing of strengthening layers, the requirements for diminishing material consumption shall be taken into consideration. For this purpose, it is applicable to use the local materials, as well as asphalt concrete with lower bonding agents. Expedience of using such materials should be verified using technical-and-economical calculations;

Heat-transfer properties of strengthening layer material should be as closer as possible to the heattransfer properties of old pavement material, in order to avoid differences in temperature deformations and creation of corresponding temperature tensions;

During constructing the strengthening layers, due attention should be given to the fact that they change the operational conditions and water-andthermal regime of entire underlying structure. The strengthening layer bears heat-insulating and distribution properties, thus improving the same properties of lower layers. The old structure improves by getting harder. All the mentioned shall be taken into consideration during performing calculations;

In the old road dress structure, the upper layer is the most vulnerable - it is usually out-of-repair and partially destroyed - this also should be paid attention to.

\section{References:}

1. Shishinashvili MT (2016) USE OF SEMIRIGID COMPOSITE PAVEMENTS IN DIFFERENT REGIONS OF GEORGIA. ISJ Theoretical \& Applied Science, 03 (35): 80-83. Soi: http://s-o-i.org/1.1/TAS-03-35-15 Doi: http://dx.doi.org/10.15863/TAS.2016.03.35.15

2. Burduladze AR, Shishinashvili MT, Magradze MD (2014) IMPROVEMENT OF THE QUALITY OF THE ASPHALT MIX. ISJ Theoretical \& Applied Science, 02 (10): 44-47. doi:

http://dx.doi.org/10.15863/TAS.2014.02.10.7

3. Shishinashvili, M. ASPHALT SURFACE RECYCLING ACCORDING TO THE HOT METHOD. inteleqtuali, 148.

4. Burduladze AR, Bezhanishvili MG, Shishinashvili MT (2014) EXISTING IN GEORGIA LOCAL ROAD CONSTRUCTION MATERIALS AND THEIR OPTIMAL USE IN THE CONSTRUCTION OF PAVEMENT. 


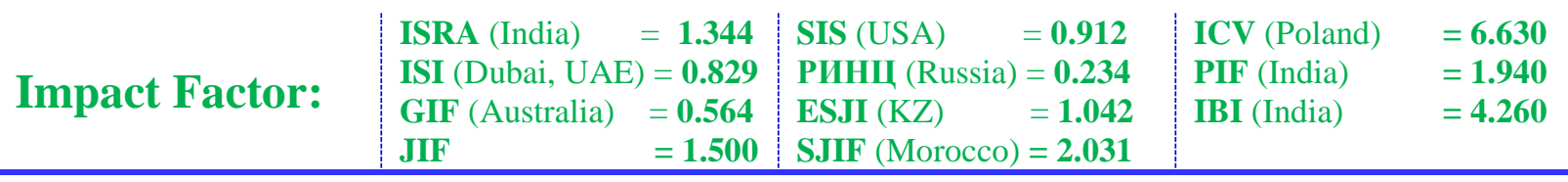

ISJ Theoretical \& Applied Science 12 (20): 6164. doi: http://dx.doi.org/10.15863/TAS.2014.12.20.14

5. Burduladze, A., Shishinashvili, M., Magradze, M., Bakuradze T (2016) PERSPECTIVES OF USE OF COLD RECYCLING IN THE ROAD SECTOR OF GEORGIA. IHJVT< B TRANSACTIONS Т Р У Д Ы, 113.

6. Shishinashvili MT (2016) AN OVERVIEW OF THE REGENERATION TECHNOLOGY OF ASPHALT CONCRETE. ISJ Theoretical \& Applied Science, 11 (43): 173-176. Soi: http://so-i.org/1.1/TAS-11-43-32

Doi: http://dx.doi.org/10.15863/TAS.2016.11.43.32

7. (2002) National Asphalt Pavement Association, ed. Design, Construction, and Maintenance of
Open-graded Asphal Friction Courses. Asphalt Institute; National Asphalt Pavement Association, 2002.

8. Goodrich, Joseph L. (1991) "Asphaltic binder rheology, asphalt concrete rheology and asphalt concrete mix properties (with discussion)." Journal of the Association of Asphalt Paving Technologists 60.

9. Erkens, Sandra Maria Johanna Grada (2002) Asphalt concrete response (acre): determination, modelling and prediction. DUP Science, 2002

10. D'Angelo, John A., et al. (2008) Warm-mix asphalt: European practice. No. FHWA-PL-08007. 2008. 